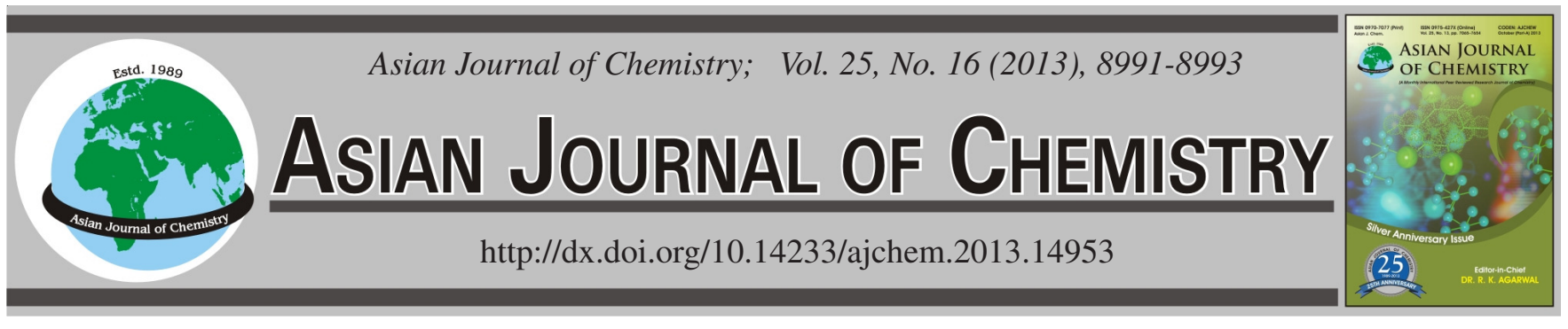

\title{
Synthesis and Characterization of an Energetic Compound (E)-4,4'-bis(tert-Butyl-N,N,O-azoxy)-3,3'-diazenofurazan
}

\author{
LiLi AN ${ }^{1, *}$, QIANQIAN $\mathrm{YU}^{2}$ and CHUFENG SuN ${ }^{1}$
}

${ }^{1}$ School of Chemical Engineering, Northwest University for Nationalities, Lanzhou 730030, P.R. China

${ }^{2}$ Shaanxi Institute of Technology, Shaanxi, Xi'an 710301, P.R. China

*Corresponding author: Fax: +86 931 4512928; Tel: +86 931 4516533; E-mail: anlili2011@163.com

A furazan-based energetic compound (E)-4,4'-bis(tert-butyl- $N, N, O$-azoxy)-3,3'-diazenofurazan (BADF) was synthesized and characterized by NMR, FT-IR spectroscopy and elemental analyses. The single crystal structure analysis revealed the symmetric BADF molecule adopted an $E$-configuration with respect to azo group $-\mathrm{N}=\mathrm{N}$ - and the torsion angle of $\mathrm{N}(2)-\mathrm{C}(1)-\mathrm{N}(1)-\mathrm{N}(1) \#$ is $161.97^{\circ}$. The planes defined by two furazan rings are parallel and their distance is only 0.404 (2) $\AA$. In the crystal structure, only van der Waals forces but obvious $\pi-\pi$ stacking were observed. Intramolecular $\mathrm{C}-\mathrm{H} \cdots \mathrm{O}$ hydrogen bonds forming two $\mathrm{S}(6)$ ring further stabilized the supramolecular sheet structure.

Key Words: Synthesis, Single-crystal structure, Furazan, Hydrogen bond.

\section{INTRODUCTION}

Compounds based on pentaheterocyclic furazan $(1,2,5-$ oxadiazole) composed of two nitrogen atoms and one oxygen atom had been widely applied into the fields of medicine $e^{1,2}$ and war industry and civil fields $s^{3-8}$. Owing to their high nitrogen content, low vulnerability, good oxygen balance, positive heat of formation, high density caused by planarity of the ring, furazan-based compound has been recognized as a promising candidate for the design and synthesis of high energetic materials $(\mathrm{HEM})^{9-12}$. Especially, these energetic materials defined as controllable storage systems of chemical energy have widely applied into the field of military and industry applications as propellants, fuels, explosives and pyrotechnics for a long time $^{13-16}$. Thus in the present work, a key intermediate $(E)$ 4,4'-bis(tert-butyl-N,N,O-azoxy)-3,3'-diazenofurazan (BADF) (Scheme-I), was synthesized and characterized by NMR, FT-IR spectroscopy and elemental analyses. Furthermore, the single crystal structure analysis was also investigated and revealed the symmetric BADF molecule adopted an $E$-configuration with respect to azo $-\mathrm{N}=\mathrm{N}$-group. Interestingly, the planes defined by two furazan rings of BADF are parallel and their distance is only 0.404 (2) $\AA$. In the crystal structure, only van der Waals forces but obvious $\pi-\pi$ stacking were observed. Intramolecular $\mathrm{C}-\mathrm{H}$... O hydrogen bonds forming two $\mathrm{S}(6)$ ring stabilize the supramolecular sheet structure.

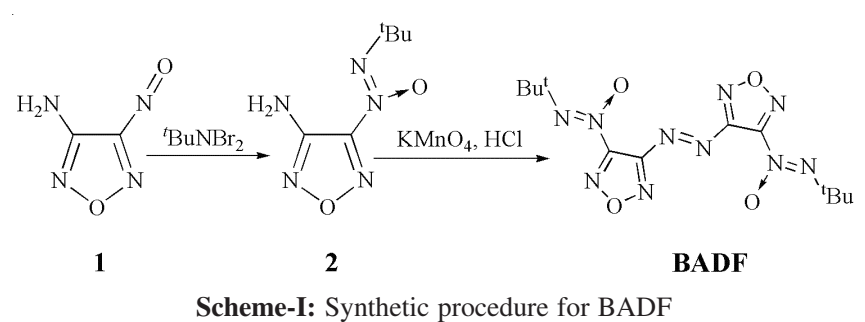

\section{EXPERIMENTAL}

$\mathrm{N}, \mathrm{N}$-Dibromo-tert-butylamine ${ }^{17}, 3$-amino-4-nitroso-furazan (1) ${ }^{18}$ and 3-amino-4-(tert-butyl- $N, N, O$-azoxy)furazan $(2)^{19}$ were prepared according to the literature procedure. X-ray single crystal structure was determined on a Bruker Smart 1000 CCD diffractometer. ${ }^{1} \mathrm{H},{ }^{13} \mathrm{C}$ and ${ }^{14} \mathrm{~N}$ NMR were obtained on a Bruker AV500 NMR spectrometer. FT-IR spectra were recorded on a VERTEX70 FT-IR spectrophotometer, with samples prepared as $\mathrm{KBr}$ pellets $\left(4000-400 \mathrm{~cm}^{-1}\right)$. Elemental analyses $(\mathrm{C}, \mathrm{H}$ and $\mathrm{N}$ ) were performed on a VARI-El-3 elemental analyzer. Melting points were measured using of a microscopic melting point apparatus made in Beijing Taike Instrument Limited Company and the thermometer was uncorrected.

Synthesis of BADF: To a suspension of 3-amino-4-(tertbutyl-NNO-azoxy)furazan (1.39 g, $7.5 \mathrm{mmol})$ in concentrated hydrochloric acid $(60 \mathrm{~mL})$, a solution of potassium permanganate $(1.42 \mathrm{~g}, 9 \mathrm{mmol})$ in water $(50 \mathrm{~mL})$ was added drop by 
drop under ice bath. Then the mixture was stirred at $55^{\circ} \mathrm{C}$ for $5 \mathrm{~h}$. After the reaction mixture was cooled to room temperature, the yellow precipitate was filtered, washed with distilled water and dried to obtain $1.16 \mathrm{~g}$ of pale-yellow solid (yield, $86 \%$ ). m.p. $128-129{ }^{\circ} \mathrm{C} .{ }^{1} \mathrm{H}$ NMR (DMSO- $d_{6}, 500 \mathrm{MHz}$ ): 1.36 (s, $18 \mathrm{H}) ;{ }^{13} \mathrm{C}$ NMR (DMSO- $d_{6}, 500 \mathrm{MHz}$ ): 156.49, 150.75, 61.28, 24.68; IR (KBr, v/cm $\left.{ }^{-1}\right): 2978,2973,1459,1450,1364,1315$, $1176,1028,903,861,683,621,484$; anal. calcd. (\%) for $\mathrm{C}_{12} \mathrm{H}_{18} \mathrm{~N}_{10} \mathrm{O}_{4}$ : C, 38.23; H, 4.95; N, 38.23; found (\%): C, 38.99; $\mathrm{H}, 5.25 ; \mathrm{N}, 37.42$.

A solution of BADF (7.3 mg, $0.02 \mathrm{mmol})$ was dissolved into $5 \mathrm{~mL}$ methanol and the solution was allowed to stand at room temperature for about one week. While the methanol was partially evaporated, several yellow block-like single crystals suitable for X-ray crystallographic analysis were obtained.

X-Ray structure determination: $X$-Ray diffraction data for BADF with approximate dimensions of $0.30 \mathrm{~mm} \times 0.20$ $\mathrm{mm} \times 0.20 \mathrm{~mm}$ were collected on Bruker Apex-II CCD diffractometer with a graphite monochromated $\mathrm{MoK}_{\alpha}$ radition $\left(\lambda=0.71073 \AA\right.$ ). Data were collected at $23(2)^{\circ} \mathrm{C}$ using the $\varphi$ and $\omega$ scan techniques. The structure was solved by direct methods and expanded using Fourier technique and refined by full-matrix least-squares method on $F^{2}$ using SHELXL97. The non-hydrogen atoms were refined anisotropically and hydrogen atoms were added theoretically. CCDC: 910940.

\section{RESULTS AND DISCUSSION}

The molecular structure of BADF has been established by single-crystal X-ray diffraction analysis. The crystallographic data and parameters for structure refinements are given in Table-1. The selected bond lengths and bond angles were listed in Table-2.

As shown in Fig. 1, X-ray crystallographic analysis revealed that the symmetric molecule of BADF, $\mathrm{C}_{12} \mathrm{H}_{18} \mathrm{~N}_{10} \mathrm{O}_{4}$, shows a 'Z' fashion molecular structure and adopts an $E$-configuration with respect to azo group $-\mathrm{N}=\mathrm{N}$ - bond and the torsion angle of $\mathrm{N}(2)-\mathrm{C}(1)-\mathrm{N}(1)-\mathrm{N}(1) \#$ (Symmetry code \#: - , $1-y,-z)$ is $161.97^{\circ}$. The planes defined by two furazan rings in the BADF molecule are parallel and distance between them is only 0.404(2) ^. The azoxy group tiltes from the neighbouring furazan ring plane, with the dihedral angle of $54.19(3)^{\circ}$, resulting in a synclinal conformation of double bonds $\mathrm{N}(3)=\mathrm{C}(2)$
TABLE-1

CRYSTAL DATA AND STRUCTURE REFINEMENT FOR BADF

\begin{tabular}{ll}
\hline Empirical formula & $\mathrm{C}_{12} \mathrm{H}_{18} \mathrm{~N}_{10} \mathrm{O}_{4}$ \\
CCDC & 910940 \\
Formula weight & 366.36 \\
Temperature $(\mathrm{K})$ & $296(2)$ \\
Wavelength $(\AA)$ & 0.71073 \\
Crystal system & Monoclinic \\
Space group & $\mathrm{P}_{1} / \mathrm{c}$ \\
Cell dimensions, $\left(\AA^{\circ},{ }^{\circ}\right)$ & $\mathrm{a}=11.427(4), \mathrm{b}=6.406(2)$, \\
& $\mathrm{c}=12.788(5), \beta=91.591(7)$ \\
Volume $\left(\AA^{3}\right)$ & $935.8(6)$ \\
$Z$; Density $($ calculated $)\left(\mathrm{mg} / \mathrm{m}^{3}\right)$ & $2 ; 1.300$ \\
$\theta$ range for data collection $\left({ }^{\circ}\right)$ & 3.6 to 27.9 \\
Absorption coefficient $\left.\left(\mathrm{mm}^{-1}\right) \mathrm{F}_{(000)}\right)$ & $0.102 ; 384$ \\
Limiting indices & $-11 \leq \mathrm{h} \leq 13,-7 \leq \mathrm{k} \leq 7,-9 \leq 1 \leq 15$ \\
Reflections collected/unique & $4038 / 1611\left[\mathrm{R}_{\text {int }}=0.0227\right]$ \\
Data/restraints/parameters & $1611 / 0 / 121$ \\
Goodness-of-fit on $\mathrm{F}^{2}$ & 1.037 \\
$\mathrm{R}[\mathrm{I}>2 \sigma \mathrm{I})]$ & $\mathrm{R}_{1}=0.044, \mathrm{wR}_{2}=0.144$ \\
Largest diff. peak and hole $\left(\mathrm{e} \AA^{-3}\right)$ & 0.23 and -0.16 \\
\hline
\end{tabular}

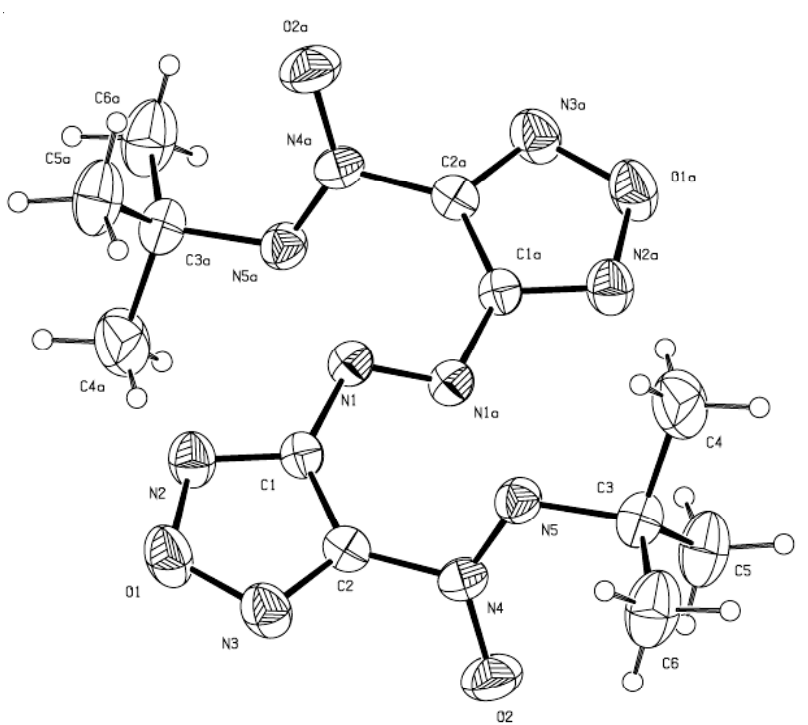

Fig. 1. Molecular structure of BADF with atom numbering scheme (symmetry scode: (a)-x, -y+1,-z). Displacement ellipsoids for non$\mathrm{H}$ atoms are drawn at the $30 \%$ probability level

and $\mathrm{N}(4)=\mathrm{N}(5)$ with torsion angle $\mathrm{N}(3)-\mathrm{C}(2)-\mathrm{N}(4)-\mathrm{N}(5)$ equal to $125.17^{\circ}$.

\begin{tabular}{|c|c|c|c|c|c|}
\hline \multicolumn{6}{|c|}{$\begin{array}{c}\text { TABLE-2 } \\
\text { SELECTED BOND DISTANCES }(\AA) \text { AND ANGLES }\left({ }^{\circ}\right) \text { FOR BADF }\end{array}$} \\
\hline Bond & Lengths & Bond & Lengths & Bond & Lengths \\
\hline $\mathrm{C}(1)-\mathrm{N}(2)$ & $1.302(2)$ & $\mathrm{C}(1)-\mathrm{N}(1)$ & $1.413(2)$ & $\mathrm{C}(1)-\mathrm{C}(2)$ & $1.423(2)$ \\
\hline$C(2)-N(3)$ & $1.284(2)$ & $\mathrm{C}(2)-\mathrm{N}(4)$ & $1.443(2)$ & $\mathrm{C}(3)-\mathrm{N}(5)$ & $1.484(3)$ \\
\hline$C(3)-C(6)$ & $1.517(3)$ & $\mathrm{C}(3)-\mathrm{C}(5)$ & $1.522(3)$ & $\mathrm{C}(3)-\mathrm{C}(4)$ & $1.527(4)$ \\
\hline $\mathrm{N}(1)-1(1)^{\#}$ & $1.249(3)$ & $\mathrm{N}(2)-\mathrm{O}(1)$ & $1.378(2)$ & $\mathrm{N}(3)-\mathrm{O}(1)$ & $1.380(2)$ \\
\hline $\mathrm{N}(4)-\mathrm{O}(2)$ & $1.256(2)$ & $\mathrm{N}(4)-\mathrm{N}(5)$ & $1.257(2)$ & - & - \\
\hline Bond & Angles & Bond & Angles & Bond & Angles \\
\hline $\mathrm{N}(2)-\mathrm{C}(1)-\mathrm{N}(1)$ & $117.7(2)$ & $\mathrm{N}(2)-\mathrm{C}(1)-\mathrm{C}(2)$ & $108.5(2)$ & $\mathrm{N}(1)-\mathrm{C}(1)-\mathrm{C}(2)$ & $133.8(2)$ \\
\hline $\mathrm{N}(3)-\mathrm{C}(2)-\mathrm{C}(1)$ & $110.1(2)$ & $\mathrm{N}(3)-\mathrm{C}(2)-\mathrm{N}(4)$ & $120.3(2)$ & $\mathrm{C}(1)-\mathrm{C}(2)-\mathrm{N}(4)$ & $129.7(2)$ \\
\hline $\mathrm{N}(5)-\mathrm{C}(3)-\mathrm{C}(6)$ & $110.0(2)$ & $\mathrm{N}(5)-\mathrm{C}(3)-\mathrm{C}(5)$ & $111.2(2)$ & $C(5)-C(3)-C(5)$ & $112.6(2)$ \\
\hline $\mathrm{N}(5)-\mathrm{C}(3)-\mathrm{C}(4)$ & $103.0(2)$ & $C(6)-C(3)-C(4)$ & 111.1(2) & $C(5)-C(3)-C(4)$ & $108.5(2)$ \\
\hline $\mathrm{N}(1)-\mathrm{N}(1)-\mathrm{C}(1)^{\#}$ & $111.7(2)$ & $\mathrm{C}(1)-\mathrm{N}(2)-\mathrm{O}(1)$ & $105.1(2)$ & $\mathrm{C}(2)-\mathrm{N}(3)-\mathrm{O}(1)$ & $104.9(2)$ \\
\hline $\mathrm{O}(2)-\mathrm{N}(4)-\mathrm{N}(5)$ & $130.9(2)$ & $\mathrm{O}(2)-\mathrm{N}(4)-\mathrm{C}(2)$ & $116.2(2)$ & $\mathrm{N}(5)-\mathrm{N}(4)-\mathrm{C}(2)$ & $112.9(1)$ \\
\hline $\mathrm{N}(4)-\mathrm{C}(5)-\mathrm{C}(3)$ & $118.2(2)$ & $\mathrm{N}(2)-\mathrm{O}(1)-\mathrm{N}(3)$ & $111.4(1)$ & - & - \\
\hline
\end{tabular}


It was noted that the presence of central azo bridge makes for slight lengthening of "internal" $\mathrm{C}(1)=\mathrm{N}(2)$ bonds (1.302(2) $\AA)$ of the furazan in comparison to "external" $\mathrm{C}(2)=\mathrm{N}(3)$ bonds (1.284(2) $\AA$ ) (Table-2), owing to the effect of conjugation of $\mathrm{N}(2)=\mathrm{C}(1)-\mathrm{N}(1)=\mathrm{N}(1) \#$. Meanwhile, the presence of the tertbutyl-NNO-azoxy results in a slight shortening of "external" $\mathrm{N}(3)-\mathrm{O}(1)$ bond $(1.380(2) \AA)$ of furazan rings in comparison to "internal" $\mathrm{N}(2)-\mathrm{O}(1)$ bond (1.378(2) $\AA$ ) (Table-2). In BADF molecule, the $\mathrm{C}=\mathrm{N}$ and $\mathrm{C}-\mathrm{C}$ bond lengths in furazan rings correspond to mean values 1.30 and $1.43 \AA$ for furazan derivatives presented in the Cambridge Structural Database ${ }^{20-22}$. Interestingly, the bond N(1)-C(1) (1.413(2) ̊) indicates some double characters, which points out conjugation between the $\pi$-system of furazan cycle C(1)-N(2)-O(1)-N(3)-C(2) and azo group.

In the crystal structure, as shown in Fig. 2, intramolecular

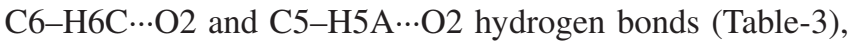
both forming two $\mathrm{S}(6)$ ring containing six-member, stabilize the supramolecular sheet structure ${ }^{23-25}$. Only van der Waals forces but obvious $\pi-\pi$ stacking were observed.

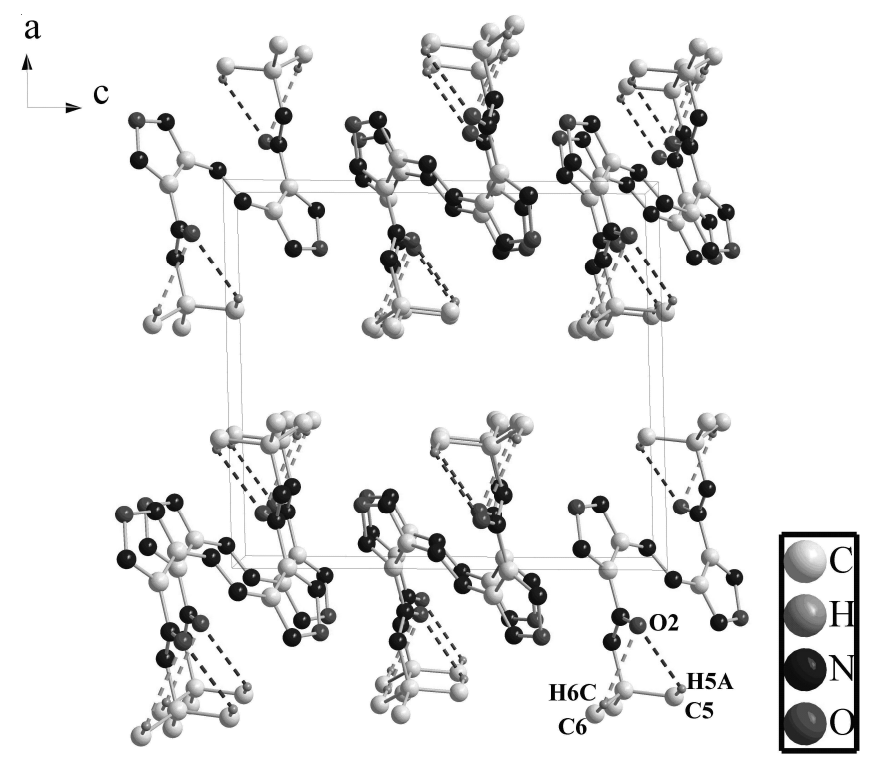

Fig. 2. Packing diagram showing intramolecular $\mathrm{C}-\mathrm{H} \cdots \mathrm{O}$ hydrogen bond viewed along the $\mathrm{b}$ axis. $\mathrm{H}$ atoms not involved in hydrogen bonding have been omitted for clarity

\begin{tabular}{|c|c|c|c|c|}
\hline \multicolumn{5}{|c|}{$\begin{array}{r}\text { TABLE-3 } \\
\text { HYDROGEN BONDS }[\AA \text { A, ๆ] FOR BADF }\end{array}$} \\
\hline D-H $\cdots A$ & $\mathrm{~d}(\mathrm{D}-\mathrm{H})$ & $\mathrm{d}(\mathrm{H} \cdots \mathrm{A})$ & $\angle \mathrm{DHA}$ & $d(D \cdots A)$ \\
\hline C5-H5A $\cdots \mathrm{O} 2$ & 0.96 & 2.41 & 115 & $2.940(3)$ \\
\hline C6-H6C $\cdots \mathrm{O} 2$ & 0.96 & 2.51 & 115 & $3.042(4)$ \\
\hline
\end{tabular}

\section{Conclusion}

A furazan-based energetic compound (E)-4,4'-bis(tertbutyl- $N, N, O$-azoxy)-3,3'-diazenofurazan (BADF) is synthesized. It was characterized by ${ }^{1} \mathrm{H},{ }^{13} \mathrm{C}$ NMR, FT-IR spectroscopy and elemental analyses. The single crystal structure analysis revealed that the symmetric molecule of BADF adopted an $E$-configuration with respect to azo group -N=Nbond and the torsion angle of $\mathrm{N}(2)-\mathrm{C}(1)-\mathrm{N}(1)-\mathrm{N}(1) \#$ is $161.97^{\circ}$. The planes defined by two furazan rings are parallel and their distance is only 0.404 (2) $\AA$. In the crystal structure, only van der Waals forces but obvious $\pi-\pi$ stacking were observed. Intramolecular $\mathrm{C}-\mathrm{H}$ … O hydrogen bonds forming two $\mathrm{S}(6)$ ring further stabilized the supramolecular sheet structure.

\section{ACKNOWLEDGEMENTS}

The work was supported by the National Natural Science Foundation of China (Grant No. 51167017).

\section{REFERENCES}

1. G.C. Tron, F. Pagliai, E.D. Grosso, A.A. Genazzani and G. Sorba, J. Med. Chem., 48, 3260 (2005).

2. R.A. Stavenger, H. Cui, S.E. Dowdell, R.G. Franz, D.E. Gaitanopoulos, K.B. Goodman, M.A. Hilfiker, R.L. Ivy, J.D. Leber, J.P. Marino, Jr., H.-J. Oh, A.Q. Viet, W. Xu, G. Ye, D. Zhang, Y. Zhao, L.J. Jolivette, M.S. Head, S.F. Semus, P.A. Elkins, R.B. Kirkpatrick, E. Dul, S.S. Khandekar, T. Yi, D.K. Jung, L.L. Wright, G.K. Smith, D.J. Behm, C.P. Doe, R. Bentley, Z.X. Chen, E. Hu and D. Lee, J. Med. Chem., 50, 2 (2007).

3. R.D. Schmidt, G.S. Lee, P.F. Pagoria, A.R. Mitchell and R. Gilardi, J. Heterocycl. Chem., 38, 1227 (2001).

4. P.F. Pagoria, G.S. Lee, A.R. Mitchell and R.D. Schmidt, Thermochim. Acta, 384, 187 (2002).

5. Y. Zhou, B. Wang, C. Zhou. J. Li, Z. Chen, P. Lian and Z. Zhang, Chin. J. Org. Chem., 30, 1044 (2010).

6. T.K. Kim, B.W. Lee and K.-H. Chung, Bull. Korean Chem. Soc., 32, 3802 (2011).

7. A.S. Kulikov, I.V. Ovchinnikov, S.I. Molotov and N.N. Makhova, Russ. Chem. Bull., Int. Ed., 52, 1822 (2003).

8. R.-H. Wang, Y. Guo, Z. Zeng, B. Twamley and J.M. Shreeve, Chem. Eur. J., 15, 2625 (2009).

9. X. Zhang, W. Zhu and H. Xiao, J. Phys. Chem. A, 114, 603 (2010).

10. A.K. Zelenin and M.L. Trudell, J. Heterocycl. Chem., 35, 151 (1998).

11. T.K. Kim, J.H. Choe, B.W. Lee and K.-H. Chung, Bull. Korean Chem. Soc., 33, 2765 (2012).

12. S.J. Qiu, Z.X. Ge, J. Jiang, T. Guo, P. Lian and X.X. Gan, Asian J. Chem., 24, 1453 (2012).

13. J. Lovas, R.D. Suenram and G.T. Fraser, J. Chem. Phys., 88, 722 (1988).

14. A.B. Sheremetev, S.E. Semenov, V.S. Kuzmin, Y.A. Strelenko and S.L. Ioffe, Chem. Eur. J., 4, 1023 (1998).

15. A.M. Churakov, S.L. Ioffe and V.A. Tartakovskii, Mendeleev Commun., 27, 20 (1996).

16. M. Hiskey, N. Goldman and J. Stine, J. Energ. Mater., 16, 119 (1998).

17. V.A. Nelson, Serianz and P. Kovacic, J. Org. Chem., 41, 1751 (1976).

18. T.M. Mel'nikova, T.S. Novikova, L.I. Khmel'nitskii and A.B. Sheremetev, Mendeleev Commun., 11, 30 (2001).

19. A.M. Churakov, S.E. Semenov, S.L. Ioffe, Y.A. Strelenko and V.A. Tartakovskii, Mendeleev Commun., 5, 102 (1995).

20. F.H.Allen, Acta Crystallogr. B, 58, 380 (2002).

21. B.B. Averkiev, M.Y. Antipin, A.B. Sheremetev and T.V. Timofeeva, Cryst. Growth Des., 5, 631 (2005).

22. E. Espinosa, E. Molins and C. Lecomte, Chem. Phys. Lett., 285, 170 (1998).

23. M. Jaworska, T. Pawlak, R. Kruszynski, M. Cwiklinska and M. Krzeminski, Cryst. Growth Des., 12, 5956 (2012).

24. E. Espinosa, M. Souhassou, H. Lachekar and C. Lecomte, Acta Cryst. B, 55, 563 (1999).

25. G.R. Desiraju, Angew. Chem., Int. Ed., 34, 2311 (1995). 